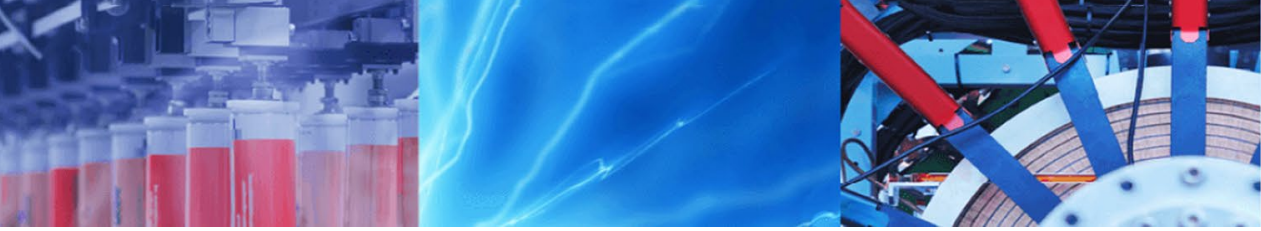

Research Article

\title{
The effect of SiC content on the tribocorrosion performance of spark plasma sintered Al-SiC nanocomposites
}

\author{
P. V. Cobbinah ${ }^{1}$ (D) W. R. Matizamhuka ${ }^{1}$
}

Received: 3 August 2019 / Accepted: 22 November 2019 / Published online: 25 November 2019

(c) Springer Nature Switzerland AG 2019

\begin{abstract}
As a follow-up study, the present work evaluates the tribocorrosion behavior of $\mathrm{Al}-\mathrm{SiC}$ nanocomposites produced using spark plasma sintering. The tribocorrosion tests were carried out using a ball-on-disk tribometer with the sliding contact fully immersed in $3.5 \mathrm{wt} \% \mathrm{NaCl}$ solution. Post-mortem characterization studies of the worn surfaces included scanning electron microscopy (SEM) coupled with an energy dispersive spectroscopy. From the results, oscillations in chronopotentiometry values characterize the in situ tribocorrosion behaviors of the composites. Shifts to the cathodic region at the beginning of sliding and immediate shift to the anodic region of the curve as sliding continues accounts for the oscillations in chronopotentiometry values. The SEM analyses infer the formation of adherent and modified tribolayers in the worn surfaces of the composites during sliding. The inert character and increasing resistance of the tribolayers enhance the tribocorrosion performance of the composites compared to the unreinforced Al alloy.
\end{abstract}

Keywords Tribocorrosion · Spark plasma sintering (SPS) · Coefficient of friction (COF) · Chronopotentiometry · Nanocomposites - Energy dispersive spectroscopy (EDS)

\section{Introduction}

The automotive industry uses $\mathrm{Al}-\mathrm{SiC}$ composites for components such as pistons, bearings, cylinder liners, driveshafts and prop shafts and most especially for brake systems owing to properties such as low density, good electrical and thermal conductivities, high damping capacity and good corrosion resistance [1-3].

Tribological properties of aluminum matrix composites (AMCs) depend on intrinsic and extrinsic factors such as reinforcement volume fraction, particle size, applied load, temperature, speed etc. Several studies on the influence of reinforcement volume fraction on wear resistance of AMCs agree that wear resistance improved as volume fraction increased [4-6]. Some studies suggested that wear rate tend to increase beyond an optimum volume fraction [7, 8]. Investigations on the effect of reinforcement particle size also indicated that wear resistance increased with increased particle sizes $[9,10]$. Conversely, other reports [11-13] suggested that adding nano- or submicron-sized reinforcement particles improved wear resistance of AMCs as well. Although individually, the reinforcement volume fraction and particle size intrinsic properties improve wear resistance, interactions between these two properties at high volume fraction and coarse reinforcement particle size negatively affect wear resistance of $\mathrm{Al}-\mathrm{SiC}$ composites [14]. Diler and Ipek [14] highlighted that AI-SiC composites exhibit the best performance against wear if the reinforcement particle size is smaller than that of the matrix particles.

Generally, the wear resistance of materials closely relates to its hardness property. In metal matrix composites (MMCs), the addition of hard ceramic reinforcing phases (such as $\mathrm{SiC}$ ) improves the hardness of the

P. V. Cobbinah, prinzcobbs@gmail.com | 'Department of Metallurgical Engineering, Vaal University of Technology, Andries Potgieter Blvd, Vanderbijlpark, Gauteng 1911, South Africa. 
composites by acting as load-carrying constituents in the composite. Nonetheless, the enhancement of MMCs hardness property has been reported to hinge on the interfacial bonding and characteristics between the metal matrix and reinforcing ceramic phase [15]. In the event of inadequate interfacial bonding resulting from fracture or fragmentation at the interface, some reinforcing particles are susceptible to be catastrophically pulled out from the matrix during sliding contact and may function as third body abrasives leading to decreased wear resistance [16-18]. With regards to corrosion, flaws or formation of anodic compounds at the metal matrix and ceramic reinforcement interface sets the interface as corrosion initiation sites or can lead to preferential corrosion attacks [19]. According to Silva et al. [20], the electrochemical behavior of composites with hard ceramic reinforcements under sliding condition can exhibit pronounced deviations from the traditional behavior of the passive metals. For instance, Toptan et al. [21] studied the tribocorrosion behavior of Ti reinforced with $\mathrm{B}_{4} \mathrm{C}$ in $9 \mathrm{~g} \mathrm{~L}^{-1} \mathrm{NaCl}$ solution. The authors inferred that under static conditions, the composites showed localized corrosion on pore sites at areas where the reinforcements agglomerated. However, under sliding, the composites exhibited lower susceptibility to corrosion and lower corrosion kinetics, owing to the loadsupporting responsibilities of the $\mathrm{B}_{4} \mathrm{C}$ reinforcements and from the decreased localized corrosion after wear debris compacted on the pores. Fang et al. [22] also reported that the increasing amount of $\mathrm{Al}_{2} \mathrm{O}_{3}$ reinforcements in $6061 \mathrm{Al}$ alloy matrix was detrimental to the corrosion resistance of the composites but had positive effects on wear corrosion. The authors asserted that with increasing $\mathrm{Al}_{2} \mathrm{O}_{3}$ contents, the less the exposed fresh surfaces of the metallic matrix to the astringent $3.5 \% \mathrm{NaCl}$ environment during sliding, hence resulting in more noble corrosion potentials.

$\mathrm{Al}-\mathrm{SiC}$ is a reactive system; hence the fabrication route influences the tribological and mechanical properties through its effects on the matrix grain size, porosity, distribution of the reinforcing phase and the reinforcement-matrix interfacial properties. Additionally, there is limited research on the tribocorrosion of AMCs compared to studies on solely wear and corrosion. Toptan et al. [17] studied the tribocorrosion behavior of $\mathrm{Al}-\mathrm{Si}-\mathrm{Cu}-\mathrm{Mg}$ alloy reinforced with $\mathrm{B}_{4} \mathrm{C}$ ( 15 and 19 vol\%) produced by squeeze casting in $0.05 \mathrm{M} \mathrm{NaCl}$ solution using the reciprocating ball-on-plate tribometer. Jamaati et al. [23] also investigated the tribocorrosion behavior of composites of $\mathrm{Al}-\left(0.48-3.55\right.$ vol\%) $\mathrm{Al}_{2} \mathrm{O}_{3}$ fabricated by anodizing and accumulative roll bonding (ARB) processes by using a ballon-plate tribometer in $1 \mathrm{wt} \% \mathrm{NaCl}$ solution. Furthermore, the tribocorrosion behavior of functionally graded aluminum matrix composites (FGAMCs) with $\mathrm{SiC}_{\mathrm{p}}$ reinforcements has also been studied [16, 18, 24].
Therefore, the present study aims to add knowledge to the tribocorrosion behavior of AMCs. The study evaluates the impact of large amounts $\mathrm{SiC}$ nano-sized additions on the tribocorrosion behavior of $\mathrm{Al}-\mathrm{SiC}$ nanocomposites produced using the solid-state process of high energy mechanical milling and spark plasma sintering (SPS) in $3.5 \mathrm{wt} \% \mathrm{NaCl}$ solution. From our previous study [25], the hardness and corrosion properties of the composites improved with increasing $\mathrm{SiC}$ additions. In the present study, the tribocorrosion performances of the composites also improve with increasing $\mathrm{SiC}$ contents. The composites form adherent tribolayers, inert and hard enough to resist the synergistic effects of wear and corrosion. Thus, Al-SiC nanocomposites in the present study offer beneficial marine application properties when used for components subject to tribocorrosion such as engine components of high-speed boats and marine diesel engines [26].

\section{Materials and methods}

Details on the synthesizing of the Al-SiC nanocomposites, their characterization and corrosion behavior are shown in our previous study [25].

For the tribocorrosion tests in the present study, the sintered $\mathrm{Al}-\mathrm{SiC}$ nanocomposites were mounted, ground and polished to $1 \mu \mathrm{m}$ mirror-like surface finish on one face. Although in real applications a mirror-like surface finish is not present, a mirror-polished finish before tribocorrosion testing in the laboratory is important because the samples' surfaces need to be flat, smooth and scratch-free. A smooth, clean and scratch-free surface significantly reduce the number of corrosion initiation sites on the composites' surface, which help to understand better and characterize the behaviors of the composites. With the face being the working surface and facing upward, samples were mounted on a ball-on-disc tribometer (Anton Paar tribometer with software Instrum $X$ 7.3.13).

A continuous unidirectional sliding test was used which included a stainless steel $316 \mathrm{~L}$ counter body of $6 \mathrm{~mm}$ diameter mounted vertically on a rotating head, above the sample. A mechanical load of $5 \mathrm{~N}$ was applied with a rotating speed of $92 \mathrm{rpm}$ (sliding speed of $2.1 \mathrm{~cm} \mathrm{~s}^{-1}$ ). The applied load on the ball drew a circular wear track of radius $2.25 \mathrm{~mm}$ on the working surface of each sample. The test was carried out at room temperature (about $25 \pm 1^{\circ} \mathrm{C}$ ) and humidity of $50 \%$. $3.5 \mathrm{wt} \% \mathrm{NaCl}$ solution was used as the corrosive environment per ASTM G44 to show better performance of the composites. The $3.5 \mathrm{wt} \% \mathrm{NaCl}$ solution is the typical salt concentration in seawater and is the most common and abundant corrosive agent on earth. For each run, the composites were immersed in a volume of $5 \mathrm{ml}$ of the $\mathrm{NaCl}$ solution. Tribo-electrochemical measurements 
were acquired using the three-electrode set-up, where the reference electrode was $\mathrm{Ag} / \mathrm{AgCl}$, the counter electrode was graphite, and the various sintered composites were the working electrode. The electrodes were connected to a VersaSTAT 4 potentiostat and linked to a PC with Versastudio software. To study the electrochemical (active or passive) state of the composites, open circuit potential (OCP) measurements were carried out.

The duration of the OCP or chronopotentiometry measurement was $3600 \mathrm{~s}$ for each run, which included $1800 \mathrm{~s}$ of rubbing. Figure 1 shows the tribocorrosion tests setup and scheme showing the position of the sample, counter body and electrodes.

Characterization of samples after tribocorrosion testing was done using the Zeiss Axio observer optical microscope and the Jeol JSM-7200F scanning electron microscope.

\section{Results and discussions}

Tribocorrosion, as defined by Landolt et al. [27], is when a material deteriorates permanently as a result of combined effects of mechanical, electrochemical and chemical processes taking place on a material surface in the presence of a corrosive environment. A general overview of the results suggests a stable passivation period, depassivation and repassivation processes and a return to the initial steady

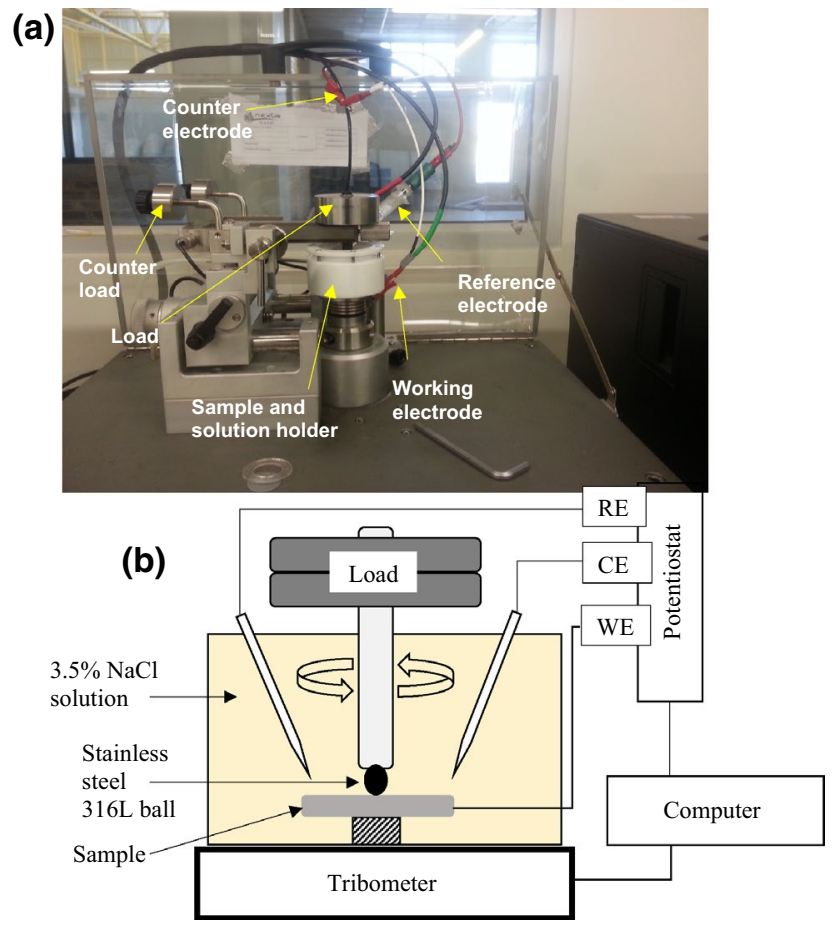

Fig. 1 a The tribocorrosion setup, b scheme showing the position of the sample, counter body and electrodes passivation potentials sum up the surface states of the composites, as shown in Fig. 2.

\subsection{Passivation period}

The formation of stable passive films characterizes the first $900 \mathrm{~s}$ of the chronopotentiometry measurements, as shown in Fig. 2. The passive films are products of the chemical interactions occurring between the Al alloy matrix and the corrosive $\mathrm{NaCl}$ environment. Innately, $\mathrm{Al}$ alloys are known to form protective films during corrosion [28] with respect to the reactions [29]:

$M \rightarrow M^{n+}+n e^{-}$

$\mathrm{mM}+\mathrm{nH}_{2} \mathrm{O} \rightarrow \mathrm{M}_{\mathrm{m}} \mathrm{O}_{\mathrm{n}}+\mathrm{H}^{+}+\mathrm{xe}^{-}$

where $\mathrm{M}$ denotes the matrix $\mathrm{Al}$ alloy. $\mathrm{SiC}$ as a hard ceramic reinforcement is recognized to be chemically inert [30]. Depending on the fabrication route and $\mathrm{SiC}$ quantities, the addition of $\mathrm{SiC}$ in some studies has been suggested to be detrimental to corrosion resistance $[19,31]$. However, from our previous study [25], the corrosion resistance of the present composites improved with increasing $\mathrm{SiC}$ additions. This was attributed to the solid-state processing route, $\mathrm{SPS}$, in which no deleterious anodic phases such as $\mathrm{Al}_{4} \mathrm{SiC}_{4}$ or $\mathrm{Al}_{4} \mathrm{C}_{3}$ formed. The formation of such anodic phases at the interface of the $\mathrm{Al}$ alloy matrix and $\mathrm{SiC}$ reinforcements favor preferentially localized corrosion attacks [32].

\subsection{Depassivation and repassivation period}

At the onset of sliding, the unreinforced alloy and composites exhibit an instantaneous shift to the cathodic region (lower potentials) of the curve followed by a shift to the anodic region (noble potentials) as seen in Fig. 2. From Fig. 2a the chronopotentiometry value of the unreinforced alloy fluctuates between -0.685 and $-0.69 \mathrm{~V}$ during sliding for $1800 \mathrm{~s}$. During unloading, the potential drops to $-0.70 \mathrm{~V}$ before "recovering" to its initial steady potential of about $-0.695 \mathrm{~V}$. Figure $2 \mathrm{~b}-\mathrm{f}$ show clearly the immediate anodic shift in chronopotentiometry value for the composites compared to that seen in the unreinforced Al alloy as sliding begins. The height of the shift correlates to the quick recovery or restoration of the formed films on the composites.

The potential shift to the cathodic region indicates an altering in the electrochemical surface states of the composites and is evidence of the removal of protective films on passive metals and alloys [33-35]. During sliding, the exposed new surfaces in contact with the $\mathrm{NaCl}$ solution become active and are subject to corrosion. This is because a galvanic cell develops between 

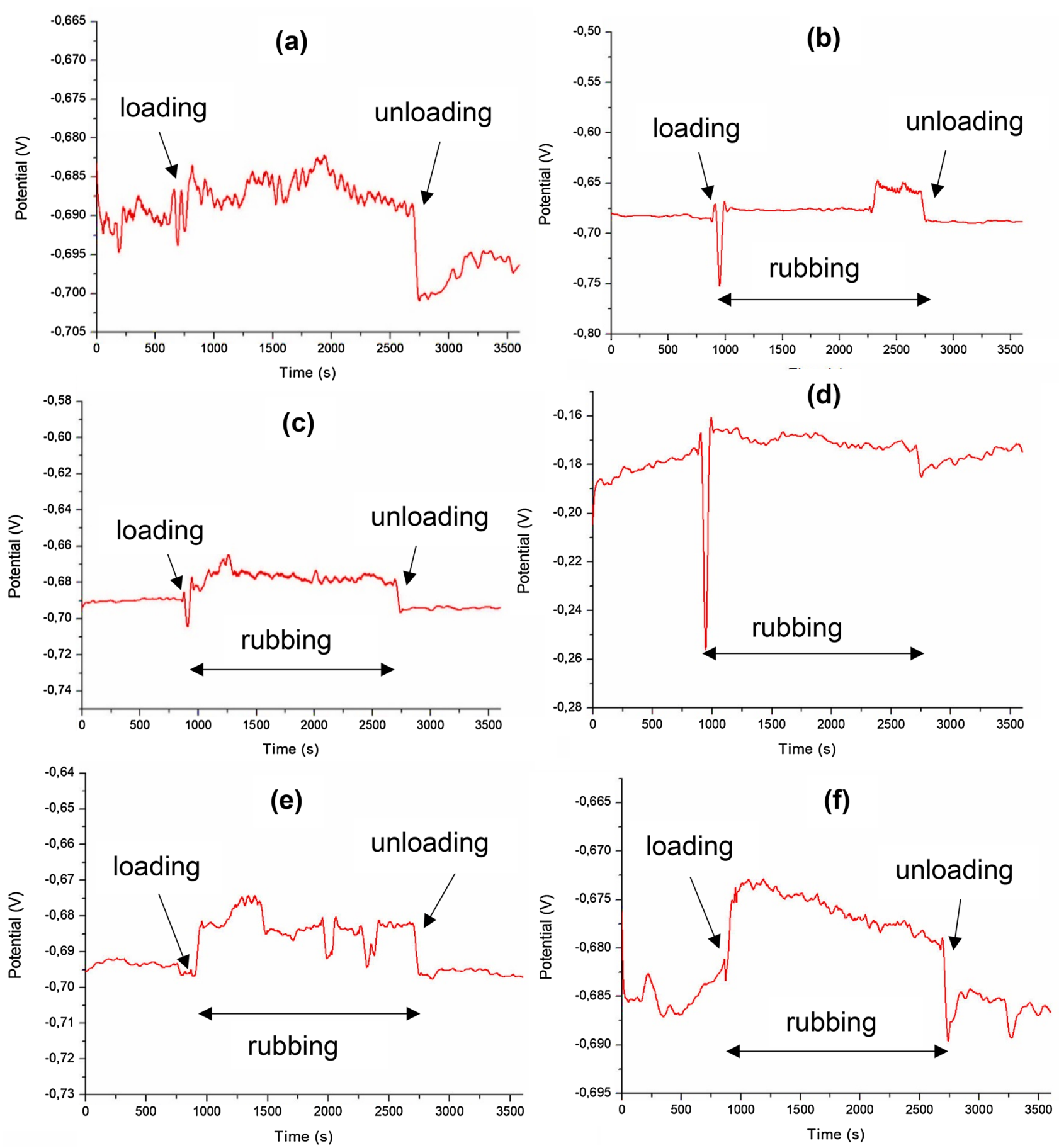

Fig. 2 Chronopotentiometry behavior of a Al alloy, b 15 wt \%, c 20 wt \%, d 25 wt $\%$, e 30 wt $\%$ and f 40 wt $\%$ SiC reinforced Al composites respectively

the worn (active) and unworn (passive) surfaces. The galvanic coupling promotes anodic dissolution in the worn regions due to the large area ratio of the passive surface to the active surface. Thus, as illustrated in Fig. 3, the worn or exposed new area shows a dark contrast compared to the unworn surface. Conversely, the shift of chronopotentiometry values to more positive potentials indicate the occurrence of repassivation or re-adsorption in the worn areas by cathodic reactions involving the reduction of dissolved oxygen as summarized by the reaction [29]: 


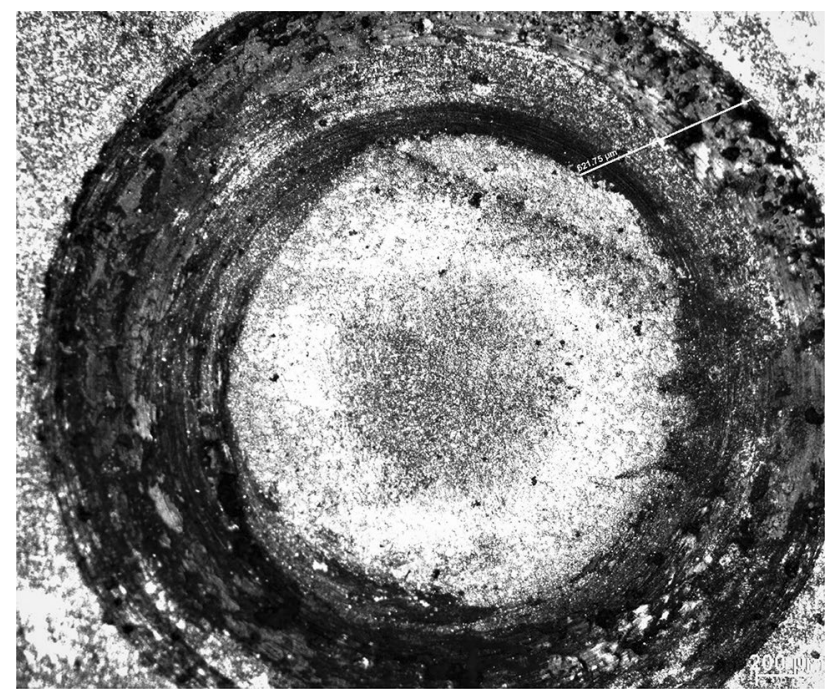

Fig. 3 Optical image of the worn surface of Al-40 wt $\% \mathrm{SiC}$ in $3.5 \mathrm{wt} \% \mathrm{NaCl}$ solution

$\mathrm{O}_{2}+2 \mathrm{H}_{2} \mathrm{O}+4 \mathrm{e}^{-} \rightarrow 4 \mathrm{OH}^{-}$

As sliding continues, competing activities due to the repassivation rate and the mechanical depassivation at the contact area of the composites manifest as potential fluctuations, as noticed in Fig. 2. The potentials measured under sliding is a mixed potential resulting from the galvanic coupling of materials found in the worn and unworn areas [27, 36, 37]. Similar chronopotentiometry trends have been reported in many studies in which the studied materials are well known to form passive protective films during corrosion [38, 39].

Furthermore, chronopotentiometry values recorded during sliding for the composites are nobler compared to their initial stable potentials. This is because the increasing $\mathrm{SiC}$ contents in the composites tend to reduce the newly exposed surfaces of the Al matrix to corrosion by the $3.5 \mathrm{wt} \% \mathrm{NaCl}$ solution [22].

\subsection{Recovery and restoration period}

The potential of the unreinforced Al alloy and the nanocomposites decrease sharply to their initial potential after sliding and removal of the applied load (Fig. 2). Within the shortest time, the stable potential behavior similar to that before sliding manifests, signifying repassivation occurring in the active area and restoration of the wear scars [27].

\subsection{Coefficient of friction (COF)}

Figure 4 shows the variation in COF during sliding under $5 \mathrm{~N}$ load for the unreinforced $\mathrm{Al}$ alloy and the $\mathrm{Al}-\mathrm{SiC}$

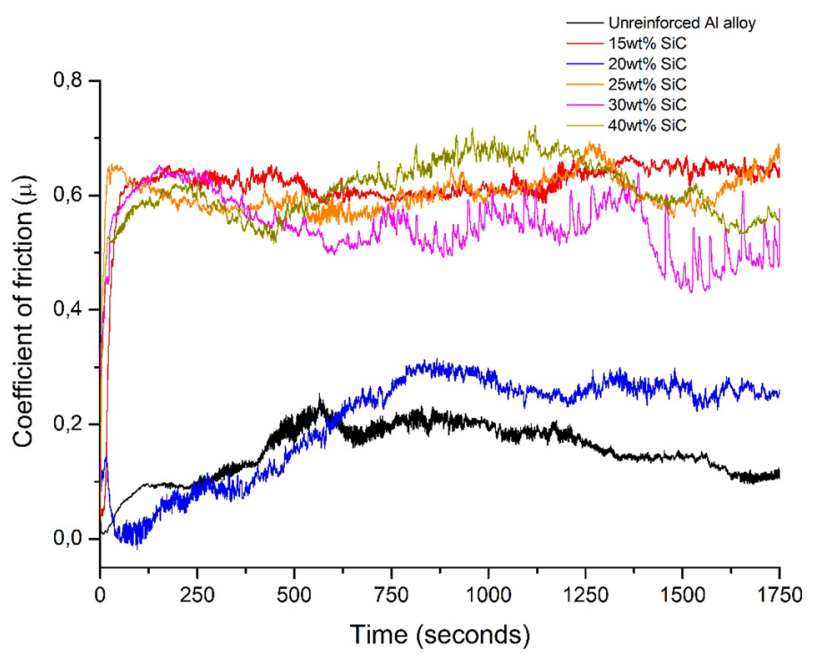

Fig. 4 Coefficient of friction of all composites under open circuit potential during the sliding period in $3.5 \mathrm{wt} \% \mathrm{NaCl}$ solution

nanocomposites. The average COF of the unreinforced $\mathrm{Al}$ alloy is 0.053 , whereas those for $\mathrm{Al}-\mathrm{SiC}$ nanocomposites range from 0.291 to 0.505 . The COF for the $\mathrm{Al}-\mathrm{SiC}$ composites increases from 0 to as high as 0.633 for the composite with $40 \mathrm{wt} \% \mathrm{SiC}$. The increase in COF of the $\mathrm{Al}-\mathrm{SiC}$ nanocomposites compared to the Al alloy may stem from the interaction between the counter body and the hard $\mathrm{SiC}$ ceramic reinforcement protruding during sliding. Furthermore, the presence of hard and oxidized wear debris freely moving at the sliding region culminating in thirdbody wear [40], can also account for the increase in COF.

The lack of smooth sliding due to the presence of reinforcing particles cause staggered motion with particle pull out being the main determinant of the actual wear rate. The direct contact of the stainless steel counter body minimizes with increased amounts of $\mathrm{SiC}$ nano-particles in the softer matrix phase, which causes particle pull out to decrease in the composites. The hard $\mathrm{SiC}$ particles counteract with the stainless steel surface, and an increase in COF is observed because of these hard particles. It has been reported that AMCs exhibit higher wear resistance than the unreinforced alloy if fracture, fragmentation, and pull out of particles are minimized or avoided [41].

Additionally, the formation of mechanically mixed layers (MML) or tribolayers on the worn surfaces from the transfer of materials from the stainless steel counter body and composites influence variations in COF values as observed in Fig. 4.

In previous studies on $\mathrm{Al}-\mathrm{SiC}_{\mathrm{p}}$ functionally graded $\mathrm{Al}$ matrix composites (FGAMCs) [16, 24], the authors concluded that the role of the $\mathrm{SiC}$ reinforcements served not only as load-bearing constituents but also promoted the formation and stability of adherent tribolayers leading to 
the improvement of wear resistance of the composites. Also, it is well known in Al-SiC composites, that the wear rate of the Al alloy matrix depends on the formation rate of the adherent tribolayer. Hence, with the increasing rate of formation of the tribolayer, the Al matrix is protected and its degradation by wear decreases [42]. Furthermore, wear-accelerated effects of the $\mathrm{NaCl}$ solution influence the tribochemistry on the wear processes. The $\mathrm{NaCl}$ solution influences the development and removal of chemical reaction products in the form of debris in the worn areas, which could affect COF.

\subsection{Worn surface morphology and composition analysis}

Figure 5 shows the SEM micrographs of the worn areas of the unreinforced $\mathrm{Al}$ alloy and composites after the tribocorrosion tests. From Fig. 5a the integrity of the formed passive layers in the worn areas of the unreinforced Al alloy is observed to be severely fractured and less resistant to the mechanical contact from the stainless steel counter body during sliding. This results in material removal or delamination in certain areas, as shown in Fig. $5 b$ and accounts for the fluctuations observed in both chronopotentiometry values and COF. Additionally, the direction of fracturing is mostly parallel to the direction of sliding. For the Al-SiC nanocomposites, exemplified by Fig. $5 c$, d, the worn surfaces are smooth. $\mathrm{SiC}$ is well known to show a smooth abraded surface [18]; thus the surface smoothness character of the nanocomposites indicate the load-bearing protective role of the nano $\mathrm{SiC}$ reinforcements which tend to resist the applied mechanical action and reduce the amount of plastic deformation.

This feature is consistent with some previous studies $[31,43]$. Feng et al. [44] reported that the presence of ceramic reinforcing phases in MMCs enhance their corrosion resistance compared to the matrix metal by functioning as an inert physical barrier on the formed passive films. Although the formed film exhibit cracks, which also are responsible for chronopotentiometry and COF fluctuations, the film shows no delamination. This demonstrates that the formed tribolayers in the nanocomposite are
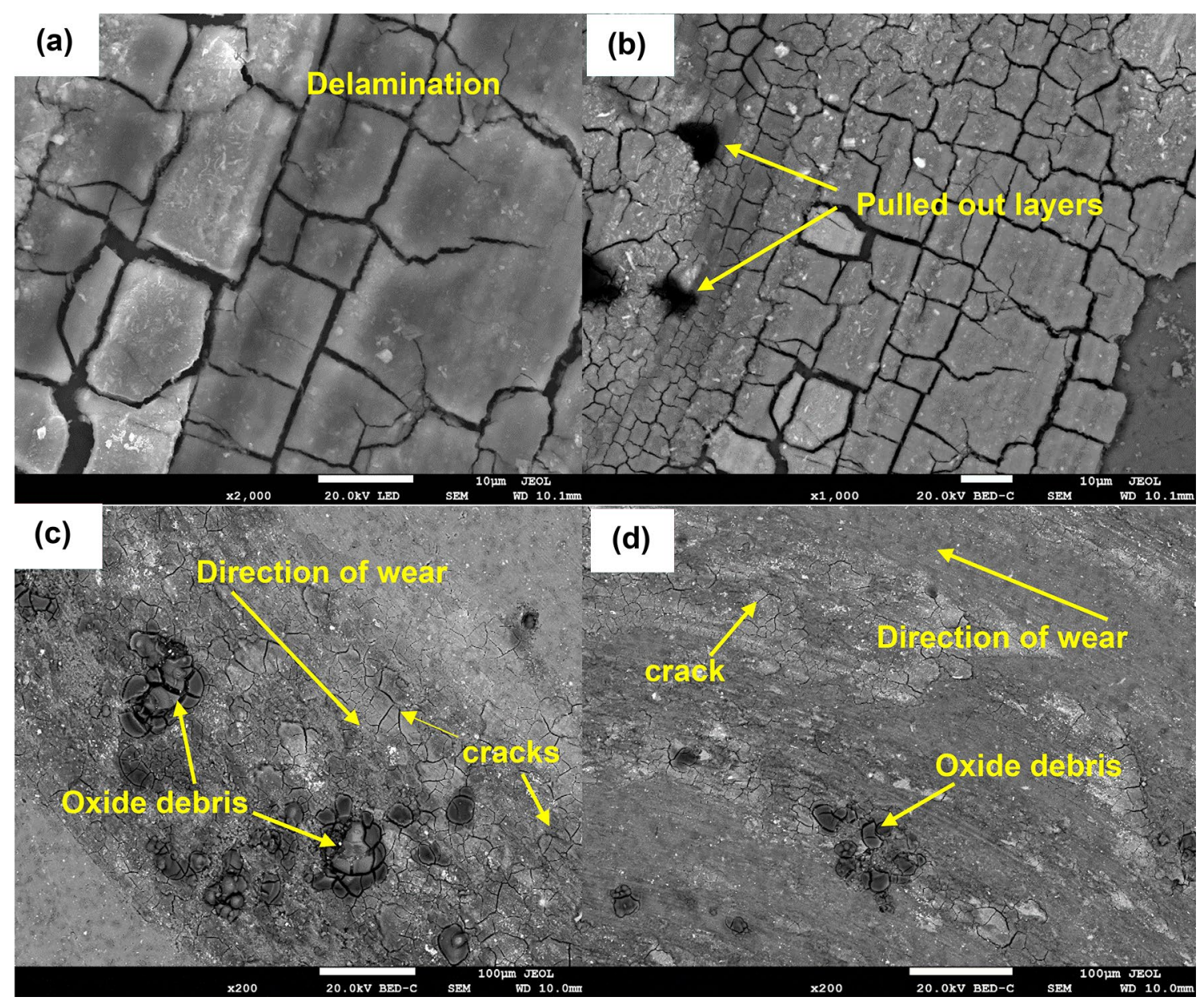

Fig. 5 SEM SE and BSE micrographs showing the wear track of $\mathbf{a}, \mathbf{b}$ the unreinforced Al alloy, $\mathbf{c} \mathrm{Al}-25 \mathrm{wt} \% \mathrm{SiC}$ and $\mathbf{d} \mathrm{Al}-30$ wt $\%$ SiC 


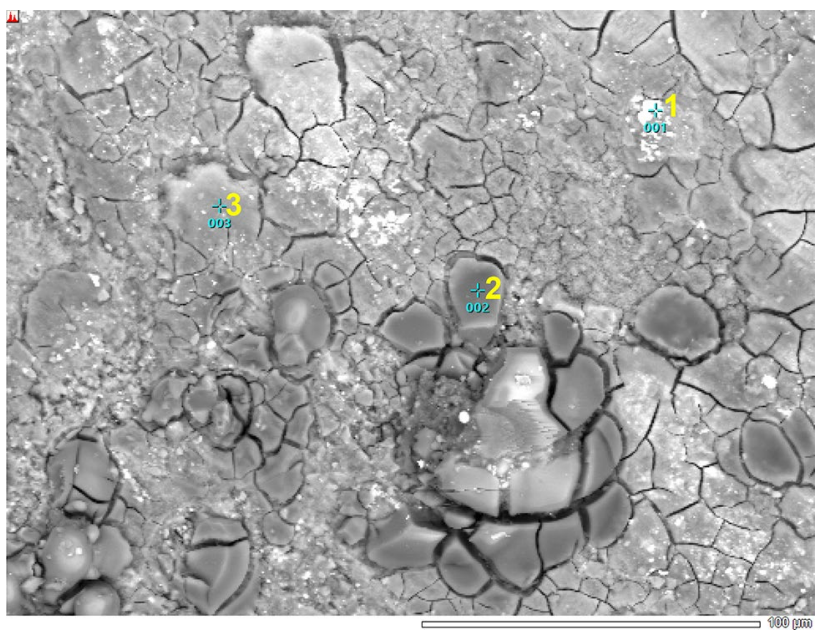

Fig. 6 SEM-EDX spot analysis of wear track of Al-25 wt\% SiC

adherent, hard enough and resistant to the mechanical contact. The resistance of the tribolayers to mechanical contact can be correlated to the composites' respective hardness properties. Consistent with our previous study, the hardness of the composites improved with increasing $\mathrm{SiC}$ amounts compared to the unreinforced Al alloy [25].

SEM-EDX spot compositional analyses (Fig. 6) shed further insight into the formed, modified tribolayers in the worn areas of the nanocomposites. The light grey contrast areas (spot 3) comprising the tribolayer are mainly of Al, $\mathrm{Si}, \mathrm{C}$ and $\mathrm{O}$. The rough dark grey regions (spot 2) are rich in $\mathrm{Al}, \mathrm{O}$ and $\mathrm{C}$. On the other hand, the white products seen in the composites and unreinforced $\mathrm{Al}$ alloy are predominant of Fe. These products are material transfer from the stainless steel counter body resulting from wear and corrosion, which are mechanically alloyed onto the tribolayer during sliding [8]. However, even though the stainless steel $316 \mathrm{~L}$ counter body slightly corrodes in the $\mathrm{NaCl}$ solution, this does not compromise the forces it exerts on the samples. This exerted force is a critical component of the wear tests.

Table 1 shows the elemental quantification from the SEM-EDX spot analysis.

In summary, the present work shows the incorporation of high amounts of $\mathrm{SiC}$ in AMCs produced using the solid-state processing route such as SPS has beneficial effects. The study indicates the increase in load-bearing capacity of the Al alloy as a result of the addition of the hard ceramic SiC reinforcing phase. Consequently, the $\mathrm{Al}-\mathrm{SiC}$ nanocomposites exhibit an increase in wear resistance. Additionally, the $\mathrm{SiC}$ reinforcing phase favors the formation of tribolayers from the transfer of materials from the counter body and protruding $\mathrm{SiC}$ phases at the worn areas of the composites. The tribolayers are inert, adherent and hard enough to resist the synergistic effects of wear and corrosion. All of the above observations in this study are consistent with previously published studies involving FGAMCs or cast AMCs with SiC $[16,22,24,42]$.

For future studies, an inert counter body will be considered to avoid any contaminations or deterioration of the counter body during testing.

\section{Conclusions}

The present study is a follow-up study [25] evaluating the tribocorrosion behavior of $\mathrm{Al}-\mathrm{SiC}$ nanocomposites with high amounts of $\mathrm{SiC}$ reinforcements synthesized using high energy mechanical ball milling and spark plasma sintering (SPS).

The fluctuations in chronopotentiometry values characterize the in situ tribocorrosion behaviors of the $\mathrm{Al}-\mathrm{SiC}$ nanocomposites in $3.5 \mathrm{wt} \% \mathrm{NaCl}$ aqueous solution. A shift of chronopotentiometry values to the cathodic region of the curve indicates the removal of formed passive layers and exposure of the new underlying surfaces to the aggressive external environment. The presence of a high-volume fraction of $\mathrm{SiC}$ in the composite and wear debris from the counter body form modified tribolayers in the worn surface. The modified tribolayers are adherent and hard enough to resist degradation by the synergistic effects of wear and corrosion. In all, the collective action of the $\mathrm{SiC}$ in increasing the load-bearing capacity of the composites and the formation of an inert physical barrier on the passive film in the worn areas of the composite, translate to the increase in wear resistance and improved tribocorrosion performance of the composites.
Table 1 Elemental quantification of SEM-EDX spot analysis (in at\%)

\begin{tabular}{llllllll}
\hline Spot & $\mathrm{C}$ & $\mathrm{O}$ & $\mathrm{Na}$ & $\mathrm{Al}$ & $\mathrm{Si}$ & $\mathrm{Cl}$ & $\mathrm{Fe}$ \\
\hline 1 & 17.52 & 16.21 & 0.56 & 10.68 & 1.17 & 0.15 & 53.7 \\
2 & 11.65 & 49.61 & 0.3 & 29.02 & 6.28 & 0.82 & 2.32 \\
3 & 31.8 & 37.83 & 0.05 & 15.11 & 11.83 & 0.83 & 2.55 \\
\hline
\end{tabular}


Acknowledgements Special thanks go to Dr. Patrick Rokebrand of the University of the Witwatersrand (Wits) for all his assistance during experimentation. Also, to Dr. Obadele and Akinwamide Samuel Olukayode of the Centre for NanoEngineering and Tribocorrosion, School of Mining, Metallurgy and Chemical Engineering, University of Johannesburg, South Africa.

\section{Compliance with ethical standards}

Conflict of interest The authors declare that they have no conflict of interest to disclose.

\section{References}

1. Miracle D (2005) Metal matrix composites: from science to technological significance. Compos Sci Technol 65(15-16):2526-2540

2. Daoud A, El-Khair MA (2010) Wear and friction behavior of sand cast brake rotor made of A359-20 vol\% SiC particle composites sliding against automobile friction material. Tribol Int 43(3):544-553

3. Rehman A, Das S, Dixit G (2012) Analysis of stir die cast Al-SiC composite brake drums based on coefficient of friction. Tribol Int 51:36-41

4. Rao R, Das S (2011) Effect of SiC content and sliding speed on the wear behaviour of aluminium matrix composites. Mater Des 32(2):1066-1071

5. Rao R, Das S (2010) Effect of matrix alloy and influence of SiC particle on the sliding wear characteristics of aluminium alloy composites. Mater Des 31(3):1200-1207

6. Tang F, Wu X, Ge S, Ye J, Zhu H, Hagiwara M, Schoenung JM (2008) Dry sliding friction and wear properties of $B_{4} C$ particulate-reinforced Al-5083 matrix composites. Wear 264(7-8):555-561

7. Mahdavi S, Akhlaghi F (2011) Effect of SiC content on the processing, compaction behaviour, and properties of Al6061/SiC/ Gr hybrid composites. J Mater Sci 46(5):1502-1511

8. Baradeswaran A, Perumal AE (2014) Study on mechanical and wear properties of Al 7075/Al $\mathrm{O}_{3}$ /graphite hybrid composites. Compos Part B-Eng 56:464-471

9. Liang Y, Ma Z, Li S, Li S, Bi J (1995) Effect of particle size on wear behaviour of SiC particulate-reinforced aluminum alloy composites. J Mater Sci Lett 14(2):114-116

10. Kwok J, Lim S (1999) High-speed tribological properties of some $\mathrm{Al} / \mathrm{SiC}_{\mathrm{p}}$ composites: I. Frictional and wear-rate characteristics. Compos Sci Technol 59(1):55-63

11. Al-Qutub A, Allam I, Qureshi T (2006) Effect of sub-micron $\mathrm{Al}_{2} \mathrm{O}_{3}$ concentration on dry wear properties of 6061 aluminum based composite. J Mater Process Technol 172(3):327-331

12. Alizadeh A, Taheri-Nassaj E (2012) Mechanical properties and wear behaviour of $\mathrm{Al}-2 \mathrm{wt} \% \mathrm{Cu}$ alloy composites reinforced by $\mathrm{B}_{4} \mathrm{C}$ nanoparticles and fabricated by mechanical milling and hot extrusion. Mater Charact 67:119-128

13. Moazami-Goudarzi M, Akhlaghi F (2016) Wear behaviour of Al 5252 alloy reinforced with micrometric and nanometric SiC particles. Tribol Int 102:28-37

14. Diler EA, Ipek R (2013) Main and interaction effects of matrix particle size, reinforcement particle size and volume fraction on wear characteristics of $\mathrm{Al}-\mathrm{SiCp}$ composites using central composite design. Compos Part B-Eng 50:371-380

15. Mondal DP, Das S (2006) High stress abrasive wear behaviour of aluminium hard particle composites: effect of experimental parameters, particle size and volume fraction. Tribol Int 39(6):470-478

16. Gomes JR, Ribeiro AR, Vieira AC, Miranda AS, Rocha LA (2005) Wear mechanisms in functionally graded aluminium matrix composites: effect of the presence of an aqueous solution. In: Van der Biest O, Gasik M, Vleugels J (eds) Materials science forum. Trans Tech, Stäfa, pp 33-38

17. Toptan F, Alves AC, Kerti I, Ariza E, Rocha LA (2013) Corrosion and tribocorrosion behaviour of $\mathrm{Al}-\mathrm{Si}-\mathrm{Cu}-\mathrm{Mg}$ alloy and its composites reinforced with $\mathrm{B}_{4} \mathrm{C}$ particles in $0.05 \mathrm{M} \mathrm{NaCl}$ solution. Wear 306(1):27-35

18. Velhinho A, Botas JD, Avila EA, Gomes JR, Rocha LA (2004) Tribocorrosion studies in centrifugally cast Al-matrix $\mathrm{SiC}_{\mathrm{p}}$-reinforced functionally graded composites. In: Martins $\mathrm{R}$, Fortunator $\mathrm{E}$, Ferreira I, Dias C (eds) Materials science forum. Trans Tech Publ, Stäfa, pp 871-875

19. Buarzaiga MM, Thorpe SJ (1994) Corrosion behavior of as-cast, silicon carbide particulate-aluminium alloy metal-matrix composites. Corrosion 50(3):176-185

20. Silva Jl, Alves AC, Pinto AM, Toptan F (2017) Corrosion and tribocorrosion behavior of $\mathrm{Ti}_{\mathrm{T}} \mathrm{TiB}-\mathrm{TiN}_{\mathrm{x}}$ in situ hybrid composite synthesized by reactive hot pressing. J Mech Behav Biomed Mater 74:195-203

21. Toptan F, Rego A, Alves AC, Guedes A (2016) Corrosion and tribocorrosion behavior of $\mathrm{Ti}^{-} \mathrm{B}_{4} \mathrm{C}$ composite intended for orthopaedic implants. J Mech Behav Biomed Mater 61:152-163

22. Fang $\mathrm{C}-\mathrm{K}$, Huang CC, Chuang TH (1999) Synergistic effects of wear and corrosion for $\mathrm{Al}_{2} \mathrm{O}_{3}$ particulate-reinforced 6061 aluminium matrix composites. MMTA 30(3):643-651

23. Jamaati R, Toroghinejad MR, Szpunar JA, Li D (2011) Tribocorrosion behaviour of aluminium/alumina composite manufactured by anodising and ARB processes. J Mater Eng Perform 20(9):1600-1605

24. Vieira AC, Rocha LA, Mischler S (2011) Influence of SiC reinforcement particles on the tribocorrosion behaviour of

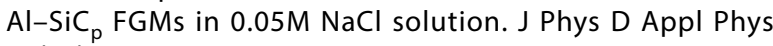
44(18):185301

25. Cobbinah PV, Matizamhuka WR (2018) The effect of SiC content on the corrosion and tribocorrosion performance of SPS produced Al-SiC nanocomposites. Afr Corros J 4:21-26

26. Prasad SV, Asthana R (2004) Aluminum metal-matrix composites for automotive applications: tribological considerations. Tribol Lett 17(3):445-453

27. Diomidis N, Celis J-P, Ponthiaux P, Wenger F (2010) Tribocorrosion of stainless steel in sulfuric acid: identification of corrosion-wear components and effect of contact area. Wear 269(1-2):93-103

28. Foley R (1986) Localized corrosion of aluminum alloys-a review. Corrosion 42(5):277-288

29. Stansbury EE, Buchanan RA (2000) Fundamentals of electrochemical corrosion. ASM International, Materials Park

30. Harti J, Prasad T, Nagaral M, Rao K (2016) Hardness and Tensile behavior of Al2219-TiC metal matrix composites. J Mech Eng Autom 6(5A):8-12

31. Singh IB, Mandal DP, Singh M, Das S (2009) Influence of SiC particles addition on the corrosion behaviour of $2014 \mathrm{Al}-\mathrm{Cu}$ alloy in 3.5\% NaCl solution. Corros Sci 51(2):234-241

32. Qian D, Zhong X, Hashimoto T, Liu Z (2015) Effect of reinforcements on the corrosion behaviour of $\mathrm{SiC}_{\mathrm{p}} / \mathrm{AA} 2124$ metal matrix composites. Corrosion 71(9):1083-1092

33. Henry P, Takadoum J, Bercot P (2011) Depassivation of some metals by sliding friction. Corros Sci 53(1):320-328

34. Zhang Y, Yin X, Wang J, Yan F (2014) Influence of microstructure evolution on tribocorrosion of 304SS in artificial seawater. Corros Sci 88:423-433 
35. Zhang Y, Yin X-Y, Yan F-Y (2016) Tribocorrosion behaviour of type S31254 steel in seawater: identification of corrosionwear components and effect of potential. Mater Chem Phys 179:273-281

36. Diomidis N, Göçkan N, Ponthiaux P, Wenger F, Celis J-P (2009) Assessment of the surface state behaviour of $\mathrm{Al}_{71} \mathrm{Cu}_{10} \mathrm{Fe}_{9} \mathrm{Cr}_{10}$ and $\mathrm{Al}_{3} \mathrm{Mg}_{2}$ complex metallic alloys in sliding contacts. Intermetallics 17(11):930-937

37. Ponthiaux $P$, Wenger $F$, Drees $D$, Celis J-P (2004) Electrochemical techniques for studying tribocorrosion processes. Wear 256(5):459-468

38. Obadele BA, Andrews A, Mathew MT, Olubambi PA, Pityana S (2015) Improving the tribocorrosion resistance of $\mathrm{Ti}_{6} \mathrm{Al}_{4} \mathrm{~V}$ surface by laser surface cladding with $\mathrm{TiNiZrO}_{2}$ composite coating. Appl Surf Sci 345:99-108

39. Diomidis N, Mischler S, More NS, Roy M (2012) Tribo-electrochemical characterization of metallic biomaterials for total joint replacement. Acta Biomater 8(2):852-859

40. Doni Z, Alves A, Toptan F, Gomes J, Ramalho A, Buciumeanu M, Palaghian L, Silva F (2013) Dry sliding and tribocorrosion behaviour of hot pressed CoCrMo biomedical alloy as compared with the cast $\mathrm{CoCrMo}$ and $\mathrm{Ti}_{6} \mathrm{Al}_{4} \mathrm{~V}$ alloys. Mater Des 1980-2015(52):47-57

41. Hutchings IM (1994) Tribological properties of metal matrix composites. Mater Sci Technol 10(6):513-517

42. Ferreira S, Sequeira P, Watanabe Y, Ariza E, Rocha L (2011) Microstructural characterisation and tribocorrosion behaviour of $\mathrm{Al} /$ $\mathrm{Al}_{3} \mathrm{Ti}$ and $\mathrm{Al} / \mathrm{Al}_{3} \mathrm{Zr}$ FGMs. Wear 270(11-12):806-814

43. Manivannan I, Ranganathan S, Gopalakannan S, Suresh S, Nagakarthigan K, Jubendradass R (2017) Tribological and surface behavior of silicon carbide reinforced aluminium matrix nanocomposite. Surf Interface 8:127-136

44. Feng $\mathrm{Q}$, Li T, Teng $\mathrm{H}$, Zhang $X$, Zhang $Y$, Liu C, Jin J (2008) Investigation on the corrosion and oxidation resistance of $\mathrm{Ni}-\mathrm{Al}_{2} \mathrm{O}_{3}$ nano-composite coatings prepared by sediment co-deposition. Surf Coat Technol 202(17):4137-4144

Publisher's Note Springer Nature remains neutral with regard to jurisdictional claims in published maps and institutional affiliations. 